\title{
Preparation and Characterization of Continuous Fe-Containing Silicon Carbide Radar Absorbing Fibers from Precursor-Based Processing
}

\author{
Zhiyan Chen ${ }^{*}, 1$, Jun Wang ${ }^{2}$, Xiaodong $\mathrm{Li}^{2}$ and Hao Wang ${ }^{2}$ \\ ${ }^{I}$ School of Materials Science and Engineering, Central South University of Forestry and Technology, Changsha 410004, \\ P.R. China \\ ${ }^{2}$ Key Lab of Advanced Ceramic Fibers and Composites, College of Aerospace and Materials Engineering, National \\ University of Defense Technology, Changsha 410073, P.R. China
}

\begin{abstract}
A new polymer polyferrocarbosilane (PFCS) was synthesized using polydimethylsilane and ferrocene as the raw materials. The polymer was then melt-spun into continuous PFCS fibers, cured in air and heat-treated in a nitrogen atmosphere up to $1300^{\circ} \mathrm{C}$, a kind of Fe-containing $\mathrm{SiC}$ fibers were finally obtained. $\mathrm{The} \mathrm{SiC}(\mathrm{Fe})$ ceramic fibers were combined with epoxy resin and a structural material was prepared showing excellent radar absorbing properties. HRTEM, XRD and XPS were used to characterize the $\mathrm{SiC}(\mathrm{Fe})$ fibers. The results show that the fibers are composed of $\beta$-SiC, amorphous $\mathrm{SiC}_{\mathrm{x}} \mathrm{O}_{4-\mathrm{x}}$, free carbon and small amount of $\mathrm{Fe}_{3} \mathrm{Si}$-like microcrystals. A carbon-enriched layer of about $120 \mathrm{~nm}$ was formed on the surface of the fibers.
\end{abstract}

Keywords: Continuous $\mathrm{SiC}(\mathrm{Fe})$ fibers, polyferrocarbosilane, radar-wave absorbing properties.

\section{INTRODUCTION}

It is well known that silicon carbide fibers prepared by precursor conversion method are one of the most promising fibers for many high-technology composites due to their high tensile strength, high Young's modulus and good oxidation resistance at high temperatures. It is interesting to study the electromagnetic properties of the fibers when they are used as functional materials. Since $\mathrm{SiC}$ fibers derived from polycarbosilane (PCS) generally have rather high specific resistance and no magnetic properties, modification of the electromagnetic properties of $\mathrm{SiC}$ fibers with hetero-atoms are necessary and attracts much attention [1].

Polytitanocarbosilane (PTCS) with $1.5-4 \%$ of $\mathrm{Ti}$ was synthesized from polydimethylsilane and titanium tetraalkoxide By Yamamura [2], and low specific resistance $\left(10^{-1} \Omega \cdot \mathrm{cm}\right)$ Si-Ti-C-O fibers \{Tyranno Lox [3] (trade name) by Ube industries, Japan $\}$ were produced from PTCS through melt-spinning, curing and pyrolysis. With a similar procedure, Si-Zr-C-O fibers [4,5] (with about $2 \%$ of $\mathrm{Zr}$ ) were prepared with polyzirconocarbosilane (PZCS) and Si-Al-C-O fibers [5-7] (with about $1 \%$ of $\mathrm{Al}$ ) from polyaluminacarbosilane (PACS) were manufactured by Ube with trade names Tyranno-ZE and Tyranno-SA, respectively. The heteroatoms in both Si-Zr-C-O and Si-Al-C-O fibers mentioned above play an important role in inhibition of crystalline grain of $\beta$-SiC at very high temperatures and thus improve the high temperature resistance.

It was reported that $\mathrm{SiC}$ fibers containing $\mathrm{Ti}$ or $\mathrm{Zr}$ may be applied as electromagnetic wave absorbing materials [3]. For

*Address correspondence to this author at the School of Materials Science \& Engineering, Central South University of Forestry \& Technology, Changsha 410004, P.R. China; Tel: +86-731-85623221; Fax: +86-731-85623303;

E-mail:spchen@163.com example, $\mathrm{SiC}$ fibers with small amount of $\mathrm{Fe}$, $\mathrm{Co}$ and $\mathrm{Ni}$ were prepared by physical mixing of the nano-meter metal particles with PCS solution by ultra-sonic processing followed by melt-spinning, curing and pyrolysis. These fibers show electromagnetic wave absorbing properties because of the existence of the magnetic metal particles [8].

In this paper, we tried to prepared a new polymer using polydimethylsilane and ferrocene as the raw materials, and studied the electromagnetic wave absorbing properties of the final $\mathrm{SiC}(\mathrm{Fe})$ fibers.

\section{EXPERIMENTAL}

\subsection{Experimental Procedure}

Polydimethylsilane (PDMS) was synthesized by dechlorination of dimethaldichlorosilane with sodium in xylene $[9,10]$. The synthesized PDMS was rearranged at $420^{\circ} \mathrm{C}$ under $\mathrm{N}_{2}$ to produce viscous liquid with some $\mathrm{Si}-\mathrm{C}$ backbone and some Si-Si groups, which was then mixed with ferrocene and reacted at $400{ }^{\circ} \mathrm{C}$ for $10 \mathrm{~h}$. PFCS was obtained through dissolving in xylene, filtration and distillation. Continuous $\mathrm{SiC}(\mathrm{Fe})$ fibers were prepared by melt-spinning PFCS at about $300^{\circ} \mathrm{C}$ using a multiple-hole nozzle, cured in air at $200{ }^{\circ} \mathrm{C}$, and heat-treated continuously at $1300{ }^{\circ} \mathrm{C}$ in a stream of nitrogen gas. The radar-wave absorbing material was obtained with this fibers and epoxy resin by hot-pressing technique.

\subsection{Characterization}

The FT-IR spectroscopy was performed using a Vector 22 spectrophotometer (Bruker, Germany) in $\mathrm{KBr}$ wafers. The XRD patterns were recorded on a D8 advance X-ray diffractometer $(\mathrm{CuK} \alpha$ radiation, $\lambda=0.15418 \mathrm{~nm})$, during which fibers were grounded into powders. XPS semiquantitative analysis of the surface of $\mathrm{SiC}(\mathrm{Fe})$ fibers were performed with an X-ray photoelectron spectroscopy 
apparatus (PHI-5702, American physics electron, $\mathrm{AlK} \alpha$ ) under ultrahigh vacuum $\left(3.4 \times 10^{-9}\right.$ torr $)$. The HRTEM micrographs were taken with a $200 \mathrm{KeV}$ high-resolution transmission electron microscope (JEOL JEM-2010FEF, Japan). The conductivity was measured in bulk with dc frequency. The microwave reflection was measured using network analyser $8720 \mathrm{ET}$ by the arc method $(180 \mathrm{~mm} \times 180 \mathrm{~mm}$ wide and $3 \mathrm{~mm}$ thick) [11].

\section{RESULTS AND DISCUSSION}

\subsection{Synthesis and Characterization of PFCS}

The FT-IR spectra of the synthesized PFCS with different percentages of ferrocene in feed are shown in Fig. (1), where PFCS-n and PCS stand for the polymers synthesized with $n$ $\mathrm{wt} \%$ and $0 \mathrm{wt} \%$ ferrocene in feed, respectively. All the samples show a similar structure with absorption bands of C$\mathrm{H}$ stretching $\left(2950\right.$ and $\left.2900 \mathrm{~cm}^{-1}\right), \mathrm{Si}-\mathrm{H}$ stretching $\left(2100 \mathrm{~cm}^{-1}\right)$, $\mathrm{CH}_{3}$ deformation of Si- $\mathrm{CH}_{3}\left(1400 \mathrm{~cm}^{-1}\right), \mathrm{CH}_{2}$ deformation in $\mathrm{Si}-\mathrm{CH}_{2}-\mathrm{Si}\left(1350 \mathrm{~cm}^{-1}\right), \mathrm{CH}_{2}$ wagging in $\mathrm{Si}-\mathrm{CH}_{2}-\mathrm{Si}\left(1020 \mathrm{~cm}^{-}\right.$ $\left.{ }^{1}\right)$, and $\mathrm{Si}-\mathrm{CH}_{3}$ rocking/Si-C stretching $\left(820 \mathrm{~cm}^{-1}\right)$ [9]. However, the $\mathrm{Si}-\mathrm{H}$ bond becomes weakened with the increasing of ferrocene. In the case of high ferrocene sample, such as PFCS-10, some small characteristic absorbing bands of $\eta^{5}-\mathrm{Cp}$ in ferrocene emerge at 3088, 1106 and $490 \mathrm{~cm}^{-1}$ [12]. Thus, PFCS can be assumed to take the following general structure, $a$ much smaller than $b$.
The results of the chemical analysis of PFCS are shown in Table 1, where the content of Fe gradually increases with more amount of ferrocene added, which is quantitatively in accordance with the above structure. It is interesting to find that the ratio of $\mathrm{C} / \mathrm{Si}$ of PFCS is close to 2.0 , while in the case of PCS, the ratio is significantly less than $2.0[9,13$, 14]. This can be explained that in the rearrangement reaction from PDMS $(\mathrm{C} / \mathrm{Si}=2.0)$ to $\mathrm{PCS}$ without ferrocene, degradation of methyl group and hydrogen free radicals occurs simultaneously to form volatile small molecules and the evaporation of large amount of $\mathrm{CH}_{4}$ leads a lower $\mathrm{C} / \mathrm{Si}$ ratio. In the presence of ferrocene, however, the degradation reaction seems less important and the resulted PFCS have a higher $\mathrm{C} / \mathrm{Si}$ ratio. In practice, we find that ferrocene also acts as a catalyst of the rearrangement reaction because it makes the reaction time much shorter even at lower temperature.

\subsection{Melt Spinning of PFCS Precursor}

The spinning parameters include spinning temperature, spinning rate and pressure. The spinning temperature depends on the melting point range of PFCS. In order to gain better spinnability, it was found that the spinning temperature was generally $50-120{ }^{\circ} \mathrm{C}$ higher than the melting point of the polymer. If the spinning temperature is too low, the melt viscosity will be too large to raise the rate of spinning, due to the cohesive rupture; and if spinning temperature is too high, the melt viscosity will be too low to remain the stability of

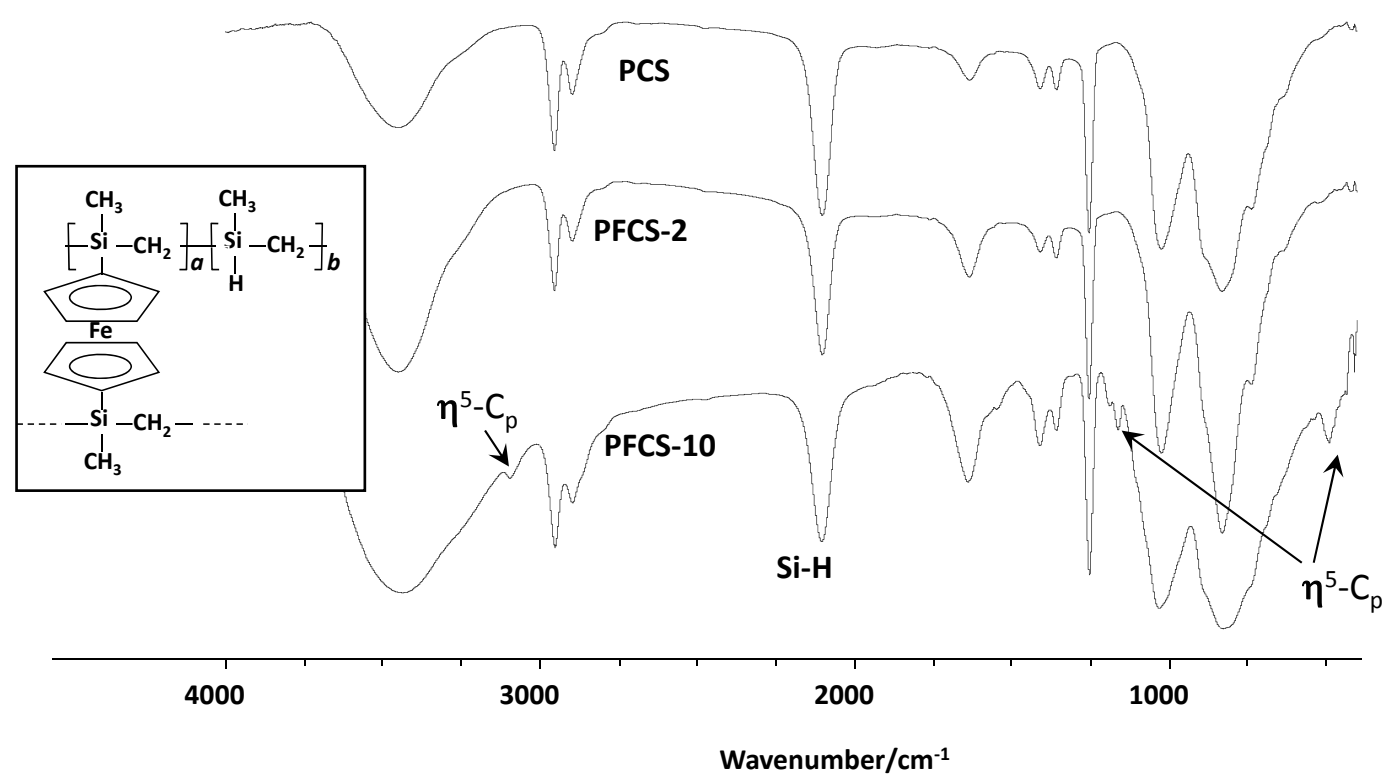

Fig. (1). FT-IR spectra of PCS and PFCS.

Table 1. Elemental Composition of PFCS

\begin{tabular}{|c|c|c|c|c|c|c|}
\hline Samples. & Cp2 Fe (wt\%) & Fe (wt\%) & Si (wt\%) & C (wt\%) & C/Si(at) & C/Si(at) in SiC Fibers \\
\hline \hline PCS & 0 & 0 & 50.2 & 40.4 & 1.88 & 1.45 \\
\hline PFCS-1 & 1.00 & 0.25 & 48.7 & 42.3 & 2.03 & 1.67 \\
\hline PFCS-2 & 2.00 & 0.57 & 48.2 & 42.3 & 2.05 & 1.70 \\
\hline PFCS-3 & 3.00 & 0.82 & 48.0 & 42.3 & 2.06 & 1.70 \\
\hline
\end{tabular}


spinning, due to the fluctuations caused by capillary rupture [15]. Fig. (2) is the relationship between fiber diameter and spinning temperature at various spinning rate, with a spinning pressure of $0.4 \mathrm{MPa}$. It can be seen the fiber diameter increases with increasing spinning temperature and lowering spinning rate.

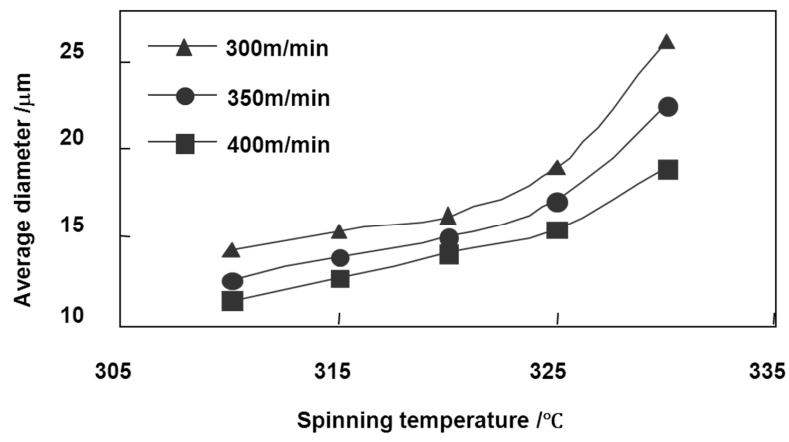

Fig. (2). The effect of spinning temperature on average diameter of PFCS green fibers.

\subsection{Exploration of Curing}

The reaction degree of the $\mathrm{Si}-\mathrm{H}$ bonds was used to evaluate the reaction progress of precrusor fibers, calculated as $\mathrm{P}_{\mathrm{Si}-\mathrm{H}}=\left[\left(\mathrm{A}_{2100} / \mathrm{A}_{1260}\right)_{\text {uncured }}{ }^{-} \quad\left(\mathrm{A}_{2100} / \mathrm{A}_{1260}\right)_{\text {cured }}\right] / \quad\left(\mathrm{A}_{2100} /\right.$ $\left.\mathrm{A}_{1260}\right)_{\text {uncured }} \times 100 \%, \mathrm{~A}_{2100}$ are the absorbance of $\mathrm{Si}-\mathrm{H}$ bonds, $\mathrm{A}_{1260}$ are the absorbance of $\mathrm{Si}-\mathrm{CH}_{3}$ bonds. It can be seen from Fig. (3), when the reaction degree of the $\mathrm{Si}-\mathrm{H}$ bonds is about $70 \%$ (by weight gain about $11 \%$ ), the continuous $\mathrm{SiC}(\mathrm{Fe})$ fibers with higher tensile strength will be achieved. The reason is that if the curing degree is not enough, the fibers might merge together, and more volatile will evaporate, which will definitely result in more defects lowering fibers strength. On the contrarily, if the curing degree is too high, after pyrolysis, more amorphous $\mathrm{SiC}_{\mathrm{x}} \mathrm{O}_{4-\mathrm{x}}$ and $\mathrm{SiC}_{\mathrm{x}} \mathrm{O}_{4-\mathrm{x}}$ structures will generate which will decompose completely and yield gaseous $\mathrm{CO}$ and $\mathrm{SiO}$, result in more defects in the fiber, thus lowering fiber strength [16].

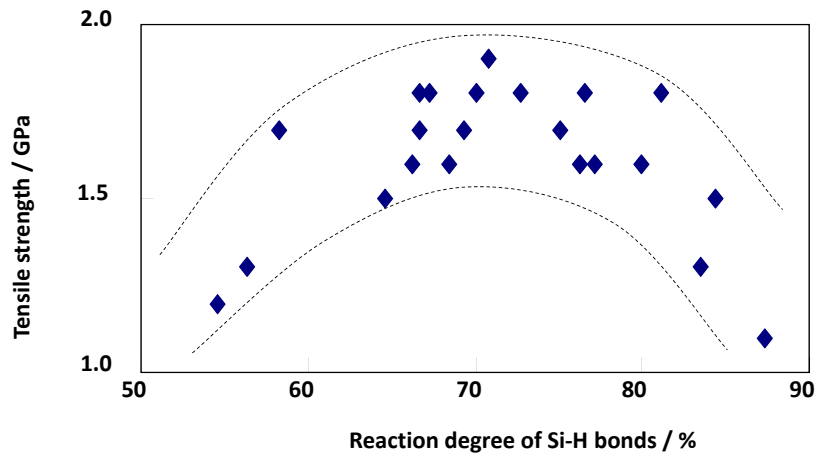

Fig. (3). The effect of reaction degree of $\mathrm{Si}-\mathrm{H}$ bonds on fibers, tensile strength.

\subsection{XPS Depth Analysis}

In Fig. (4), XPS depth elementary profiles of continuous $\mathrm{SiC}(\mathrm{Fe})$ fibers show that a carbon-enriched layer of about $120 \mathrm{~nm}$ was formed on the surface, $\mathrm{C} / \mathrm{Si}$ mole ratio is about 1.3 in the fiber core, and $\mathrm{O}$ and $\mathrm{Fe}$ atomic concentrations are about $15 \%$ and $2 \%$, respectively, and there are some $\mathrm{Fe}_{3} \mathrm{Si}-$ like microcrystals in the fibers. The fluctuation of the elementary composition may be due to the heterogenious distribution of small amount of $\mathrm{Fe}$ atoms.

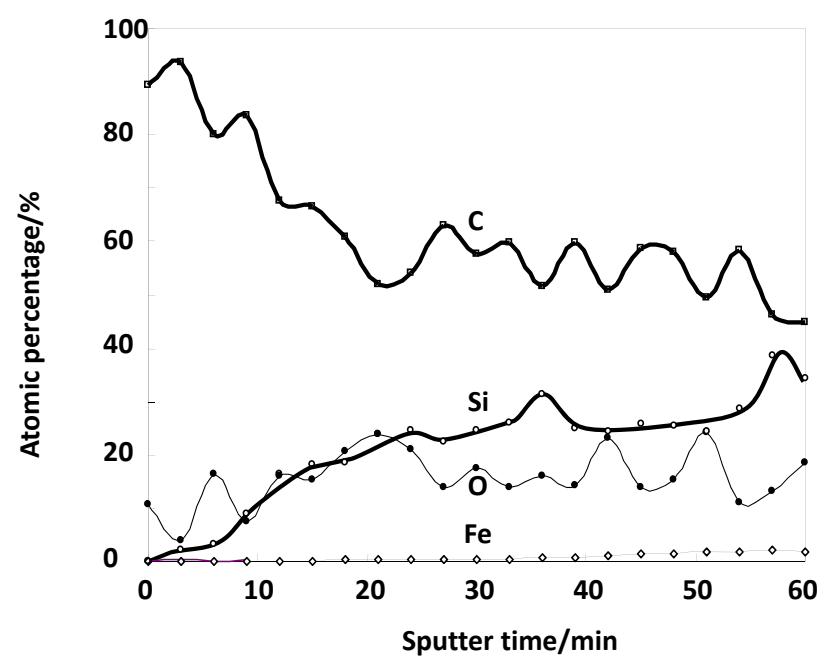

Fig. (4). The distribution of the elements in the diametric direction of continuous $\mathrm{SiC}(\mathrm{Fe})$ fibers by XPS depth analysis (Etching rate $15 \mathrm{~nm} / \mathrm{min}$, etching degree $45^{\circ}$ ).

\subsection{XRD Analysis}

From the XRD patterns of $\mathrm{SiC}(\mathrm{Fe})$ fibers shown in Fig. (5), it is obvious that higher amount of ferrocene in PFCS or the content of $\mathrm{Fe}$ in the fibers leads to sharper diffraction peaks. The crystalline grain sizes were estimated, using Scherrer equation from the 111 peak of $\beta-\mathrm{SiC}$ at $2 \theta=$ $35.6^{\circ}$ [5], to be $1.8,3.1,3.3,4.2$ and $93.4 \mathrm{~nm}$ for $\mathrm{SiC}$, $\mathrm{SiC}(\mathrm{Fe})-1, \mathrm{SiC}(\mathrm{Fe})-2, \mathrm{SiC}(\mathrm{Fe})-3$ and $\mathrm{SiC}(\mathrm{Fe})-10$ (powder) respectively. Therefore, $\mathrm{Fe}$ contained in the $\mathrm{SiC}(\mathrm{Fe})$ fibers seems to accelerate the growth of $\beta$-SiC crystals in the pyrolysis process. In addition, for the high $\mathrm{Fe}$ content sample (Fig. 5a), some new diffractions at $2 \theta=45.34^{\circ}, 66.05^{\circ}$ and $83.75^{\circ}$ emerge, which may possibly be assigned to $\mathrm{Fe}_{3} \mathrm{Si}$ as 220,400 and 422 respectively.

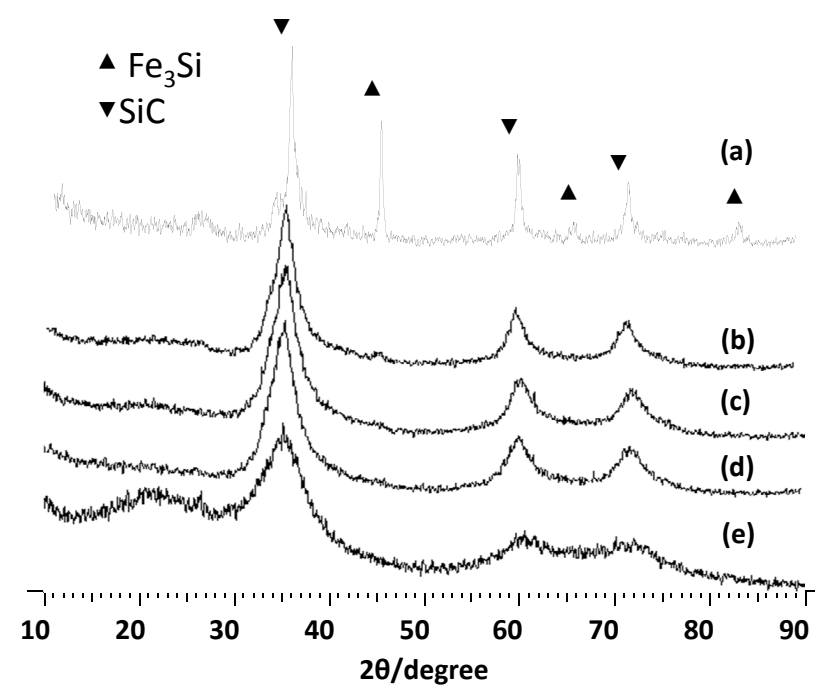

Fig. (5). XRD patterns of $\mathrm{SiC}, \mathrm{SiC}(\mathrm{Fe})$ fibers and a powder as a comparison. (a) $\mathrm{SiC}(\mathrm{Fe})-10$ /powder, (b) $\mathrm{SiC}(\mathrm{Fe})-3$, (c) $\mathrm{SiC}(\mathrm{Fe})$ 2, (d) $\mathrm{SiC}(\mathrm{Fe})-1$, (e) $\mathrm{SiC}$. 

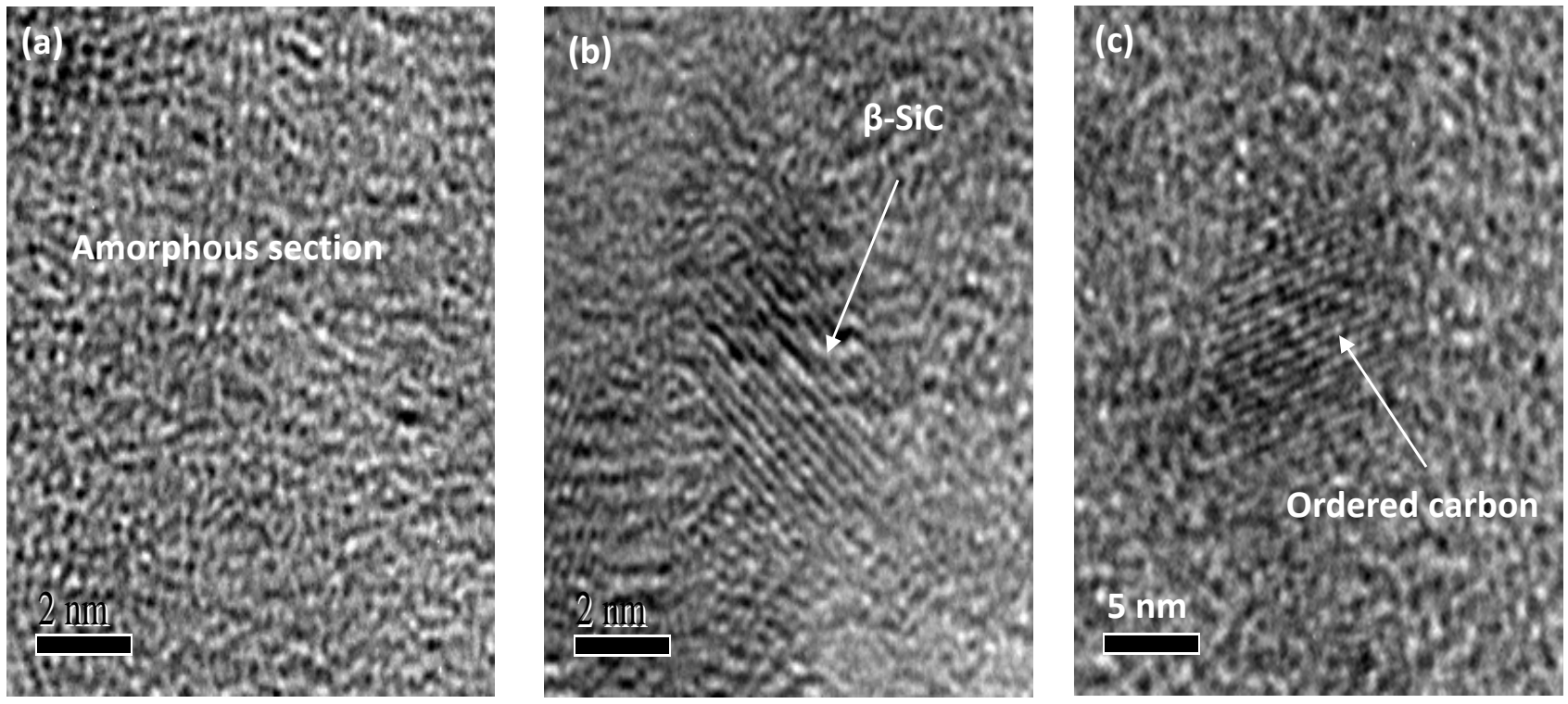

Fig. (6). HRTEM images of the continuous $\mathrm{SiC}(\mathrm{Fe})$ fibers.

\subsection{HRTEM Analysis}

High-resolution electron micrographs of continuous $\mathrm{SiC}(\mathrm{Fe})$ fibers are shown in Fig. (6). Fig. (6a) is considered to be in the amorphous state consisting of $\mathrm{Si}, \mathrm{C}, \mathrm{O}$ and a trace amount of Fe. In Fig. (6b), the lattice image corresponding to a $0.25 \mathrm{~nm}$ interlayer spacing of $\beta-\mathrm{SiC}(111)$ planes is observed in some areas of continuous $\mathrm{SiC}(\mathrm{Fe})$ fibers. In Fig. (6c), the lattice image corresponding to a $0.335 \mathrm{~nm}$ interlayer spacing is assigned to ordered free carbon. So continuous $\mathrm{SiC}(\mathrm{Fe})$ fibers are primarily composed of amorphous $\mathrm{SiC}_{\mathrm{x}} \mathrm{O}_{4}$ $x$, small amount crystallization of $\beta-\mathrm{SiC}$ and free carbon. A small number of $\beta$-SiC and free carbon are distributed in amorphous $\mathrm{SiC}_{\mathrm{x}} \mathrm{O}_{4-\mathrm{x}}$.

\subsection{Radar Wave Absorbing Properties}

Fig. (7) shows the reflection attenuation curve of radarwave absorbing material having a size of $180 \mathrm{~mm} \times 180 \mathrm{~mm} \times 2 \mathrm{~mm}$, which was prepared with continuous $\mathrm{SiC}(\mathrm{Fe})$ fibers and epoxy resin by the thermal-pressure technique. The composite exhibits a reflection attenuation peak of $-15.4 \mathrm{~dB}$ at $12 \mathrm{GHz}$. The reflection band below $-10 \mathrm{~dB}$ is in the frequency region of 10 to $14 \mathrm{GHz}$, up to $4 \mathrm{GHz}$, indicating an excellent radar-wave absorbing property.

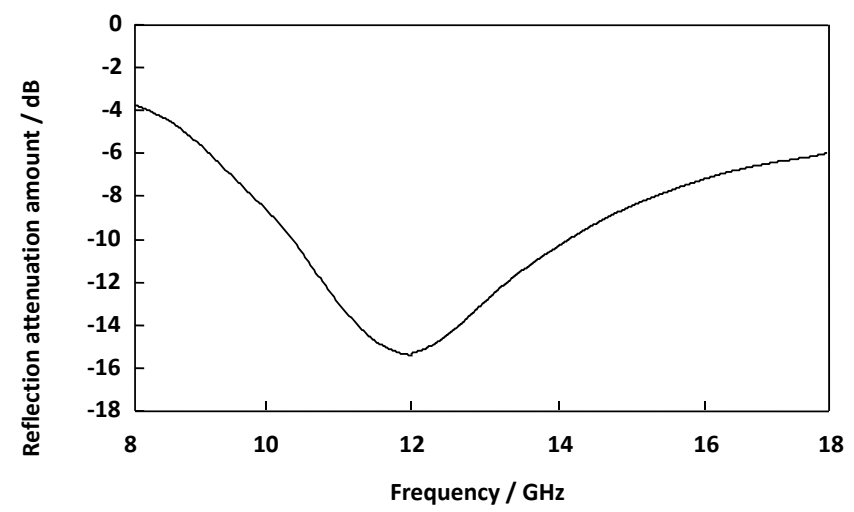

Fig. (7). The curve of reflection attenuation amount of $\mathrm{SiC}(\mathrm{Fe})$ absorbing materials.

\section{CONCLUSIONS}

A new pre-ceramic polymer, polyferrocarbosilane (PFCS), was synthesized from polydimethylsilane and ferrocene. The precursor was melt-spun into fibers, cured in air, pyrolyzed above $1200^{\circ} \mathrm{C}$ in nitrogen and continuous $\mathrm{SiC}(\mathrm{Fe})$ fibers were obtained. The $\mathrm{SiC}(\mathrm{Fe})$ fibers showed good radar wave absorbing properties, namely, $4 \mathrm{GHz}$ band below $-10 \mathrm{GHz}$ at the thickness of $2 \mathrm{~mm}$. The continuous $\mathrm{SiC}(\mathrm{Fe})$ fibers were composed of amorphous $\mathrm{SiC}_{\mathrm{x}} \mathrm{O}_{4-\mathrm{x}}$ phase, $\beta$-SiC crystalline phase, small amount of $\mathrm{Fe}_{3} \mathrm{Si}$ crystalline phase and free carbon phase, which were confirmed in XPS, XRD and HRTEM analyses.

\section{ACKNOWLEDGEMENT}

Declared none.

\section{CONFLICT OF INTEREST}

Declared none.

\section{REFERENCES}

[1] Narisawa M, Itoi Y, Okamura K. Electrical resistivity of Si-Ti-C-O fibers after rapid heat treatment. J Mater Sci 1995; 30: 3401-6.

[2] Yamamura T, Isgikawa T, Shibuya M. Development of a new SiTi-C-O fiber using an organometallic polymer precursor. J Mater Sci 1988; 23: 2589-94

[3] Yamamuna T, Toshikawa T, Shibuya M. Electromagnetic wave absorbing material. USP 1992; 5094907.

[4] Ishikawa T, Kohtoku Y, Kumagawa K. Production mechanism of polyzirconocarbosilane using zirconium (IV) acetylacetonate and its conversion of the polymer into inorganic materials. J Mater Sci 1998; 33: 161-6.

[5] Dong SM, Chollon G, Labrugere C. Characterization of nearly stoichiometric SiC ceramic fibres. J Mater Sci 2001; 36: 2371-81.

[6] Cao F, Li XD, Peng P, Feng CX, Wang J. Structural Evolution and Associated Properties on Conversion from Si-C-O-Al Ceramic Fibers by Sintering. J Mater Chem 2002; 12: 606-10.

[7] $\mathrm{Yu} \mathrm{YX}, \mathrm{Li} \mathrm{XD}$, Cao F, et al. Preparation and properties of continuous Al-containing silicon carbide fibers. Trans Nonferrous Met Soc China 2005; 15: 510-4.

[8] Wang J, Song YC, Feng CX. Pyrolysis of polycarbosilane/ nanoferrum particles. Chinese J Mater Res 1998; 12: 195-8. 
[9] Yajima S, Hasegawa Y, Hayashi J. Synthesis of continuous silicon carbide fiber with high tensile strength and high young's modulus. J Mater Sci 1978; 13: 2569-76.

[10] Soraru GD, Babonneau F, Mackenzie JD. Structural evolutions from polycarbosilane to SiC ceramic. J Mater Sci 1990; 25: 388693.

[11] Xie W, Cheng HF, Chu ZY, et al. Radar absorbing properties of light radar absorbing materials based on hollow-porous carbon fibers. J Inorg Mater 2009; 24: 320-4.

[12] Yu Z, Zhou XG, Bai ZP, Zhou Y, Liu RC. Mossbauer spectroscopy by using transmission integral evaluation technique: a application for the studies of polyferrocene. J Inorg Chem 1997; 13: 38-42.
[13] Chu ZY, He RA, Zhang XB, et al. Fabrication of porous $\mathrm{SiCy}($ core $) / \mathrm{C}$ (shell) fibers using a hybrid precursor of polycarbosilane and pitch. Carbon 2010; 48: 2115-8.

[14] Cheng XZ, Xiao JY, Xie ZF, Song YC, Wang YD. Composition and structure characterization of polycarbosilane synthesized from polydimethylsilane under high pressure. J Natl Uni Def Tech 2005; 27: 20-3.

[15] Wan JW, Zheng WW, Song YC, et al. Study of polycarbosilane melt spinning mixed with nanometer particles. China Synth Fiber Ind 1997; 20: 9-12.

[16] Mah T, Affe MJ, Mccullum DE. Thermal stability of SiC fibers (Nicalon). J Mater Sci 1984; 19: 1191-201.

(C) Chen et al:; Licensee Bentham Open.

This is an open access article licensed under the terms of the Creative Commons Attribution Non-Commercial License (http://creativecommons.org/licenses/by-nc/3.0/) which permits unrestricted, non-commercial use, distribution and reproduction in any medium, provided the work is properly cited. 